\title{
Invisibilidades, resistências e re-existências em revistas femininas
}

Invisibilities, Resistances and Re-Existences in Women's Magazines

\author{
Geovana Quinalha Oliveira' (iD) 0000-0003-3538-9362
}

'Universidade Federal de Mato Grosso do Sul, Faculdade de Artes, Letras e Comunicação, Campo Grande, MS, Brasil.79070-900 - letras.faalc@ufms.br

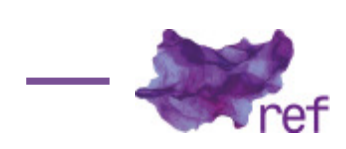

BITTELBRUN, Gabrielle.

Cores e contornos: Gênero e raça em revistas femininas do século 21.

Florianópolis: Editora Insular, 2018, 388p.

Para as garotas que se veem mal no espelho, para as garotas que mal se veem nas páginas. (Gabrielle BITTELBRUN, 2018)

Embora não seja comum escolher como epígrafe a dedicatória de um livro, faço-o para demonstrar o impacto que as palavras de Gabrielle Bittelbrun provocaram em mim e em tantos outros corpos "que mal se veem nas páginas". Cores e contornos: gênero e raça em revistas do século 21 é o título da obra a partir da qual a autora evidencia o modo como as ausências e as presenças de corpos dissidentes são manipulados nas revistas brasileiras Claudia, TPM e AzMina, conhecidas por se enquadrarem no hall de magazines femininos, considerando público-alvo e abordagem. Aqui, nomeio como dissidência todos os corpos de mulheres que não se adequam ao difundido padrão eurocêntrico: branca, magra, jovem, heterossexual.

Muito além de uma simples constatação do lugar/não-lugar das mulheres dissidentes - leiase mulheres negras, indígenas, gordas, homossexuais, bissexuais, cis, trans - nas revistas em questão, o livro de Bittelbrun revela, entre outros fatores, a falta e a existência enquanto elementos recorrentes no campo das representações de produção do simbólico na sociedade e, por extensão, o silenciamento e a hierarquização de algumas mulheres em relação a outras. A autora reconhece que investigar presenças consiste, necessariamente, em um estudo das ausências. Dessa maneira, no itinerário da proposta de Bittelbrun, verifica-se uma análise minuciosa que interpela a forma como esses magazines, cada um a seu modo, denotam os silenciamentos, as estigmatizações e as coisificações de determinados corpos, fato que indica como as relações de poder se estabelecem na constituição do imaginário social em relação a gênero, raça, sexualidade, lugar e classe.

Nesse sentido, a autora problematiza como as mulheres em sua diversidade são narradas ou inenarradas nesses espaços midiáticos, cujo conteúdo é bastante divergente quando o assunto é a representatividade, colocando em xeque uma suposta unidade entre as mulheres, seus interesses e experiências, ao mesmo tempo em que questiona a predominância de uma visão simplista e superficial de oposição entre o eu e a alteridade.

A pesquisadora desnaturaliza invisibilizações praticadas em diferentes narrativas das edições de Claudia e TPM publicadas entre os anos de 2004 a 2014, sobretudo em relação às mulheres negras, que, vistas pela ótica predominante do eurocentrismo, de um lugar que se 
convencionou chamar de ocidental, carregam ausências acionadas por meio de estruturas de opressão sistematizadas. Tais ausências as levam a ocupar o lugar de uma inferioridade desumana, sentenciando-as à margem, seja no trabalho, nas artes, na publicidade, na cultura, na política, enfim, na própria história. São questões que desembocam em discussões sobre políticas de representatividade e, especialmente, em embates acerca da constituição de normas linguísticas e corpóreas que estruturam e enquadram as mulheres em categorias hierárquicas, hegemonicamente marcadas em termos de raça, classe, gênero, lugar e sexualidade.

Vale ressaltar que essas categorias são analisadas por Gabrielle Bittelbrun a partir de um posicionamento interseccional. Não há no livro construção de capítulos ou mesmo subcapítulos que discutam ora uma categoria, ora outra. Como sugerem Avtar Brah e Ann Phoenix, essas categorias são tecidas conjuntamente porque "as diferentes dimensões da vida social não podem ser separadas em vertentes discretas e puras" (BRAH; PHOENIX, 2017, p. 663). É no âmago das identidades das mulheres outras, das quais fala Bittelbrun, que encontramos a concepção de identidade fraturada a partir da qual se abre o conceito de interseccionalidade. Elaborada pelas feministas negras dos anos de 1980, a interseccionalidade assenta-se na proposição de um pensamento relacional e articulado das categorias de classificação dos sujeitos. Em vista disso, é possível detectar e compreender as diversas escalas e articulações da opressão, bem como construir resistências que contemplem as demandas das mulheres em suas multiplicidades, como aponta Cores e Contornos.

Em contraponto a Claudia e TPM, a autora inclui em sua pesquisa a revista eletrônica AzMina. Sua análise contempla o recorte temporal entre os anos de 2015 (data de seu lançamento) a 2017. Segundo a pesquisadora, apesar de Claudia e TPM trazerem diversas pautas feministas em suas edições, não se observa uma manifestação explícita de que são magazines feministas, diferentemente de AzMina, cujo editorial declara abertamente seu posicionamento político feminista e de empoderamento de mulheres não padronizadas.

Apesar do livro considerar uma série de questões relativas às mulheres, o corpo como forma de existência/resistência/re-existência é, sem dúvida, uma das temáticas mais exploradas por Bittelbrun. O lugar dos corpos dissidentes nas revistas é questionado insistentemente pela autora, que corrobora a pergunta de Sojourner Truth em relação às mulheres negras: "por acaso não sou uma mulher?" (TRUTH, 2014). Nas palavras da pesquisadora, é preciso pensar "o que envolve o processo de significação nas revistas e como operam os mecanismos de representação, e também de representatividade" (BITTELBRUN, 2018, p. 19), uma vez que representar pode ter a conotação de ocupar o lugar do outro, tirá-lo da jogada, de modo que as regras não incluam subjetividades e idiossincrasias outras, a exemplo das experiências, do modo de ser e sentir das mulheres negras. O corpo, como se sabe, é "um lugar de inscrições, produções ou constituições sociais, políticas, culturais e geográficas" (Elizabeth GROSZ, 2000, p. 84) e, assim, seus usos pela indústria cultural devem ser analisados.

Se a mudança passa pela adesão social, o trabalho marcadamente interseccional de Bittelbrun abraça a luta antirracista e denuncia a cultura falsamente cordial e multicultural que tenta ocultar a intolerância e o descaso com a mulher negra. Como bem pontua Audre Lorde, um futuro potencialmente democrático depende da capacidade de identificarmos e desenvolvermos novos modelos de convivência com a diferença "porque as ferramentas do senhor jamais desmontarão a casa do senhor" (LORDE, 2019, p. 248).

Eis a razão pela qual a escolha de Bittelbrun, por analisar o modo como é construída a representatividade em revistas femininas, a partir das estruturas de poder das quais derivam 0 preconceito e o racismo, tenha sido tão acertada. Segundo a autora, Claudia comete, em maior e menor grau, violências simbólicas marcadas pela ausência daquilo que foge ao modelo linear e hegemônico do feminino, além de endossar, repetidamente, uma "verdade" sobre os corpos, como se fosse uma norma. Nas capas analisadas de Claudia, por exemplo, o cabelo afro inexiste e, invisibilizar, é negar. De acordo com Antonia Quintão, "a exclusão simbólica, a não-representação ou distorções da imagem da mulher negra nos meios de comunicação são formas de violência tão dolorosas, cruéis e prejudiciais que poderiam ser tratadas no âmbito dos direitos humanos" (apud Sueli CARNEIRO, 2003, p. 125). Ademais da ausência, a pesquisadora reitera a necessidade do debate em termos de protagonismo e empoderamento das mulheres negras em contraposição à ideia da erotização e do mito da mestiçagem como fator de democracia racial, muitas vezes vinculadas às suas imagens.

Cores e contorno aponta para o fato de que, entre 2004 e 2014, apenas três mulheres negras protagonizaram a capa de Claudia: Taís Araújo, Camila Pitanga e Débora Nascimento. As três atrizes autodeclaram-se negras e são conhecidas na mídia por seus envolvimentos com debates sobre questões de gênero e raça. Ainda nesse período, constatou-se que algumas celebridades que estiveram na capa da revista, como Ivete Sangalo, Juliana Paes, Patricia Poeta, Glória e Cléo Pires, Luiza Brunet e Dira Paes, apesar de carregarem traços de outras etnias, como indígena e afrodescendente, seguiram reforçando um padrão de branquidade que leva o público a considerá- 
las como brancas. Bittelbrun destaca que intervenções no corpo e no cabelo, por meio de diversos recursos, acabam por camuflar alguns traços e aproximá-las muito mais dos ideais estéticos caucasianos, reiterando aquilo que Sueli Carneiro (2016) chamou de "fuga da negritude". Seja como for, tem-se, portanto, nesse período, $81 \%$ das capas de Claudia representadas por mulheres predominantemente brancas, enquanto $5 \%$ das capas foram ocupadas por mulheres negras. Em $14 \%$ dos casos, o destaque foi conferido àquelas personalidades que, embora tenham traços de outras etnias, são igualmente consideradas brancas. Logo, o que se vê nessa revista é uma ação de branquitude aceita e reforçada, pois, certamente, atende aos olhares de quem as consome.

Em relação à TPM, pode-se dizer que um dos marcadores da diferença está justamente em suas capas. Com uma proposta mais vanguardista e inclusiva, a revista protagoniza corpos outros em suas capas, sugerindo um tom de crítica aos padrões sociais e às demais revistas do setor, como aponta a pesquisadora. Mas é no interior de sua construção que se observa uma certa timidez em cumprir a promessa de se manter diferenciada de outros magazines, como anunciado em seu primeiro editorial: "Eu não sou".

Ao longo de 388 páginas, Gabrielle Bittelbrun analisa os avanços de TPM e as similaridades com Claudia em relação não só às capas, como também aos conteúdos no interior das revistas. Desde suas seções fixas às reportagens "soltas" é possível perceber construções e atualizações de um certo ideal feminino, seus estereótipos e, por extensão, seus efeitos em uma sociedade que ainda não rompeu com normas hegemonicamente marcadas em termos de raça, etnia, classe, lugar e sexualidade. Contudo, pesquisas como as de Bittelbrun nos indicam que outros caminhos estão sendo trilhados, visto que trazem para discussão a necessidade de avaliarmos diariamente as relações existentes entre imagem, linguagem, subjetividade e poder. Com efeito, assim, oportunizam-se reformulações de estratégias feministas para políticas de coalização em uma perspectiva mais plural e dialógica, cuja finalidade é redefinir a própria noção de identidade.

Da teoria à prática, Cores e contorno mostra a corporalidade enquanto produto social, cultural e político marcado institucionalmente pela rejeição às diferenças. As indagações acerca da pouca representatividade da figura da mulher não hegemônica no imaginário político do público de alguns magazines é um enfrentamento, uma intervenção na forma como compreendemos e falamos sobre as subjetividades das mulheres negras, por exemplo, na indústria cultural. No entanto, a análise específica de Bittelbrun a respeito de AzMina renova nossas esperanças na construção de revistas femininas que desafiam tautologias conservadoras e que sejam subversivas e disruptivas, quando a tela e as páginas são emolduradas pelas mulheres negras e pelos signos da negritude. Conforme a pesquisadora, os gestos de desobediência de AzMina ressaltam incidências plurais do imaginário a partir do protagonismo de mulheres negras, mas também de mulheres cis, trans, lésbicas, bissexuais, gordas, ciganas, indígenas, brancas, magras; sem, contudo, deixar de pontuar as dificuldades e as opressões enfrentadas por todas elas.

A revista define-se como uma forma de jornalismo independente. Na seção "Quem somos" (2017), verifica-se a política do magazine em só aceitar patrocinadores cujas modelos contratadas tenham índices de massa corporal considerados saudáveis pela Organização Mundial da Saúde (OMS). Ainda no âmbito financeiro, buscam-se colaborações coletivas e recursos angariados por meio de palestras e consultorias da organização AzMina, da qual a revista faz parte. Assim como Claudia e TPM, AzMina aborda temáticas de moda, comportamento, sexualidade, esportes, cultura e política, porém, a revista, como acentua Bittelbrun (2018, p. 328): "parece unir, com viés feminista, aspectos dessas publicações para o público feminino com características do jornalismo informativo". A autora aponta que AzMina não descarta recursos já conhecidos, como listas de dicas de entretenimento e reportagens investigativas, todavia, o caráter transgressor fundamentase pelas escolhas das personagens que não costumam circular nos espaços midiáticos hegemônicos, desestabilizando, desse modo, as discriminações e hierarquias. Por conseguinte, a busca por representatividade, sugerida desde o slogan AzMina - que tenta promover as mulheres de A a Z - manifesta-se, por exemplo, nas capas do portal, que não traz imagens de celebridades. Nas matérias, verifica-se um universo marcadamente heterogêneo em que a diferença é tratada positivamente uma vez que seu corpo editorial entende a necessidade e a seriedade do empoderamento como consciência crítica e revolucionária pela igualdade e equidade. Nesse sentido, observa-se, segundo Bittelbrun, uma busca por ampliar a capacidade de agenciamento conferida às mulheres, aumentando tanto o leque de representadas como o universo de temas contemplados.

Se é certo que não podemos dizer o "quanto as personagens de revista contribuíram para nossos ideais de hoje, [...] é fato que as reivindicações de hoje podem mudar quem estará na capa amanhã e como estará" (BITTELBRUN, 2018, p. 360). Em Cores e contornos há um compromisso ético por enfrentamentos e propostas de mudanças fundamentais em todas as esferas da cultura, em especial às imagens simbólicas em revistas que a cada página nos dizem como fomos, como somos e para onde seguimos. 


\section{Referências}

BRAH, Avtar; PHOENIX, Ann. "Não sou uma mulher? Revisitando a interseccionalidade". In. BRANDÃO, Izabel; CAVALCANTI, Ildney; COSTA, Claudia de Lima; LIMA, Ana Cecília Acioli (Orgs.). Traduções da cultura: Perspectivas Críticas Feministas (1970-2010). Florianópolis: EDUFAL; Editora da UFSC, 2017, p. 661-684.

BITTELBRUN, Gabrielle Vivian. Cores e contornos: gênero e raça em revistas femininas do século 21. Florianópolis: Insular, 2018.

CARNEIRO, Sueli. "Mulheres em movimento". Revista Estudos Avançados, São Paulo, v. 17, n. 49, p. 117-133, 2003.

CARNEIRO, Sueli. "Negros de pele Clara". CEERT, 20/10/2016 às 13:00. Disponível em: https://www. ceert.org.br/noticias/educacao/13956/sueli-carneiro-negros-de-pele-clara. Acesso em: 20/01/2019.

GROSZ, Elizabeth. "Corpos reconfigurados”. Cadernos Pagu, Campinas, n. 14, p. 45-86, 2000.

LORDE, Audre. "Idade, raça, classe e gênero: mulheres redefinindo a diferença". In. HOLLANDA, Heloisa Buarque de (Org.). Pensamento feminista: conceitos fundamentais. Rio de Janeiro: Bazar do tempo, 2019, p. 239-249.

TRUTH, Sojourner. "Eu não sou uma mulher?". Trad. de Osmundo Pinho. Geledés, 08/01/2014. Disponível em: https://www.geledes.org.br/e-nao-sou-uma-mulher-sojourner-truth/. Acesso em: 15/01/2019.

Geovana Quinalha Oliveira (geovanaquinalha@yahoo.com.br) é doutora em Literatura pela Universidade Federal de Santa Catarina (UFSC), possui Mestrado em Letras, com ênfase em estudos literários pela Universidade Federal de Mato Grosso do Sul (2007). Atualmente é professora adjunta da Universidade Federal de Mato Grosso do Sul (UFMS). É editora da Revista Rascunhos Culturais. Tem experiência na área de Letras, com ênfase em literatura brasileira, atuando principalmente nos seguintes temas: estudos feministas e decoloniais.

\section{COMO CITAR ESSE ARTIGO DE ACORDO COM AS NORMAS DA REVISTA}

OLIVEIRA, Geovana Quinalha. "Invisibilidades, resistências e re-existências em revistas femininas". Revista Estudos Feministas, Florianópolis, v. 28, n. 1, e66133, 2020.

CONTRIBUIÇÃO DE AUTORIA

Não se aplica.

FINANCIAMENTO

Não se aplica.

CONSENTIMENTO DE USO DE IMAGEM

Não se aplica.

APROVAÇÃO DE COMITÊ DE ÉTICA EM PESQUISA

Não se aplica.

CONFLITO DE INTERESSES

Não se aplica.

LICENÇA DE USO

Este artigo está licenciado sob a Licença Creative Commons CC-BY International. Com essa licença você pode compartilhar, adaptar, criar para qualquer fim, desde que atribua a autoria da obra.

HISTÓRICO

Recebido em 08/07/2019

Aprovado em 01/12/2019 